\title{
Viabilidade econômica de duas hortas hidropônicas na área urbana da cidade de São Paulo
} Economic feasibility of two hydroponic gardens in the urban area of São Paulo city

$$
\text { Erico Murilo Gozzi }{ }^{1 *} \text {; Michel Augusto Santana da Paixão² }
$$

${ }^{1}$ ESALQ/USP - Avenida Conceição, 97, Carandirú -02072-000 - São Paulo, SP - Brasil <erico-pc@outlook.com>

2 UENP - Doutor em Economia Aplicada, PR 160, Km 0 (saída para Leópolis) - CEP 86300-000 - Cornélio Procópio, PR - Brasil

\section{Resumo}

A hidroponia, por não fazer uso do solo, permite maior flexibilidade na localização da horta, característica importante considerando-se os desafios de se alimentar uma população crescente que deve chegar a 9 bilhões de habitantes em 2050. O desafio dessa nova realidade é aproximar os produtores, atualmente na zona rural, dos consumidores dos grandes centros urbanos. O objetivo foi verificar a viabilidade econômica de dois projetos de horta de alface hidropônica no ambiente urbano da cidade de SP. O primeiro projeto considerou a construção de uma horta hidropônica com iluminação natural em um terreno localizado em um bairro centralizado da zona norte da cidade de São Paulo. O projeto previu a construção das bancadas dentro de uma estufa, ambos orçados no projeto. O segundo projeto considerou o cultivo das alfaces em galpão com iluminação artificial em LED e vários andares de cultivo. As diferenças entre os projetos permitiram a comparação dos impactos de inclusão das tecnologias utilizadas em fazendas virtuais no resultado financeiro das hortas. O estudo iniciou com a definição da localização das hortas, seguido da elaboração do fluxo de caixa, e do cálculo de indicadores de desempenho. Foram calculados os indicadores de Valor de Patrimônio Líquido [VPL], Taxa Interna de Retorno [TIR] e payback descontado. Foi também realizada uma análise para verificação do impacto da inclusão de novos andares na horta vertical. Por fim, verificou-se que o projeto de hidroponia com iluminação artificial, apesar da pequena área da edificação considerada, é viável para implantação em ambiente urbano.

Palavras-chave: alface, ambiente urbano, fazenda vertical, fluxo de caixa, hortaliças

\begin{abstract}
Hydroponics, by not using soil, allow greater flexibility in garden's location due to no, an important feature considering the challenges of feeding a growing population that should reach 9 billion inhabitants by 2050 , according to UN data. This growth creates the challenge to bring producers, nowadays in the countryside, closer to big center consumers. Thefore, the objective of this article was to verify the economic viability of two projects of hydroponic lettuce in the urban environment of SP city. The first project considered the construction of a hydroponic vegetable garden with natural light in a north zone neighborhood of São Paulo city. The project predicted the construction of benches inside a greenhouse, both budgeted in the project. The second project considered cultivation of alfalfa sheds with artificial LED lighting and several floors of cultivation. The differences between the projects allowed was considered the estimated impact of including virtual farms' technologies. The study began with the definition of the garden's location, followed by the cash flow estimation, and performance indicators calculation. The indicators of Net Present Value [NPV], Internal Rate of Return [IRR] and "Payback" discounted were calculated. An analysis was also carried out to verify the impact of new floors inclusion in a vertical garden. Finally, it was verified that the hydroponic project with artificial lighting is feasible for implantation in an urban environment despite the small area of the building.
\end{abstract}

Keywords: vegetables, lettuce, cash flow, vertical farm, urban environment

\section{Introdução}

O modo de cultivo classificado como hidroponia refere-se ao cultivo de plantas sem a utilização do solo. Apesar de sua utilização relativamente recente, este tipo de técnica já existia em outros períodos da história humana, como por exemplo, os jardins suspensos da Babilônia e os jardins flutuantes astecas e chineses (Resh, 2013).
Em comparação com a agricultura tradicional, a hidroponia possui como principal desvantagem maior custo para montagem de sua estrutura. Em contrapartida, provê nutrição mais eficiente das plantas contribuindo para maior produtividade e uso mais racional de fertilizantes e água. Por não fazer uso do solo, a hidroponia permite maior flexibilidade na localização da horta, possibilitando um planejamento 
mais eficaz para que esteja mais próxima dos centros consumidores, especialmente os centros urbanos.

Estimativas apontam que a população global deverá situar-se por volta de 9 bilhões de habitantes em 2050, sendo que $70 \%$ dessas pessoas estarão vivendo em centros urbanos (Kozai et al., 2014).

Em face desta realidade, novas técnicas e soluções tecnológicas estão sendo desenvolvidas para atender à crescente demanda alimentar dessa população urbana. Assim, as fazendas verticais consistem no plantio de vegetais em espaço fechado, tais como fábricas e galpões, utilizando iluminação artificial. Esta nova técnica de cultivo é chamada de "Indoor Vertical Farming System - Plant Factory with Artificial Lightning” [PFAL] (Kozai et al., 2014).

No Brasil, em virtude das condições climáticas favoráveis e de sua extensão territorial, não há ainda grande uso desta técnica. Porém, em se tratando de regiões urbanas no Brasil, como em São Paulo, segundo dados do SEADE (2016), a população na região metropolitana de São Paulo deverá aumentar em aproximadamente 1,5 milhões, totalizando 22 milhões de pessoas até 2030. Com o crescimento populacional, é esperado também um aumento na frota de veículos da região metropolitana. Segundo dados do DENATRAN (2016), a frota de veículos medida em dezembro de 2016 na cidade de São Paulo é de 7.805.127 que, somados as estimativas de crescimento populacional, tendem a aumentar consideravelmente no decorrer dos anos, dificultando a distribuição de alimentos pela cidade.

Uma maneira de melhorar a logística de distribuição de alimentos é investir em soluções que aproximem os produtores do mercado consumidor. Frente a essa realidade, a construção de fazendas verticais em ambiente urbano permitirá que produtores tenham acesso direto aos seus consumidores, sem a necessidade de grandes deslocamentos para entrega de seus produtos.

Em comparação com uma horta de hidroponia tradicional, que faz uso de iluminação natural, a fazenda vertical é plantada em espaços fechados com uso de iluminação artificial. Por conta disso, utiliza-se de várias soluções tecnológicas para controle do ambiente de forma a simular as condições obtidas na natureza. Essa moderação impacta em um maior custo de investimento e manutenção, mas, em contrapartida, permite um melhor aproveitamento do espaço de plantio além de reduzir os riscos de pragas nas hortaliças (Kozai et al., 2014).

Uma forma de avaliar objetivamente se esse tipo de solução é financeiramente rentável, é a realização de um estudo de viabilidade econômica comparando os resultados obtidos com a inclusão dessas novas técnicas em relação à hidroponia tradicional, já utilizada em território brasileiro (Fonseca, 2012).
O trabalho teve por objetivo realizar o estudo de viabilidade econômica de dois projetos de hidroponia (tradicional e vertical) construídos em ambiente urbano para produção de alface.

\section{Material e Métodos}

A execução do estudo encontra-se definida nas seções seguintes. Inicialmente foi escolhida a localização das hortas. Em seguida, foram levantados os custos e receita esperados referentes a cada um dos projetos. Por fim, foi definida uma Taxa Mínima de Atratividade [TMA] e calculado os indicadores de rentabilidade para possibilitar a comparação entre os dois projetos.

Afim de avaliar os impactos dos andares de horta presentes no projeto de hidroponia vertical, foi realizada no final desta seção uma análise de sensibilidade da TIR e do custo do pé de alface a partir de uma simulação de inclusão de novos andares no projeto.

\section{Localização}

Foi definida a região de Santana, Zona Norte da cidade de São Paulo, como a localização das hortas. Esta escolha é justificada por se tratar de um bairro centralizado da zona norte, com alta densidade demográfica (9.361 hab km²) (Prefeitura de São Paulo, 2016) e o preço do metro quadrado ser o menor, se comparado a outras regiões da cidade. O modelo de negócio de ambos os projetos prevê a venda das alfaces produzidas para os varejistas da região.

Para montagem da infraestrutura, foram levantados dados em sítios eletrônicos especializados em locação de imóveis dos tipos galpão e terreno na região de Santana. A metragem mínima desejada dos imóveis pesquisados foi de $200 \mathrm{~m}^{2}$, com distribuição da área de $10 \mathrm{~m} \times 20 \mathrm{~m}$.

\section{Projeto de Hidroponia Tradicional}

O projeto de hidroponia tradicional prevê a construção de uma estufa de $126 \mathrm{~m}^{2}$ (7 m x $\left.18 \mathrm{~m}\right)$ sobre terreno de $10 \mathrm{~m}$ × $20 \mathrm{~m}$. O valor orçado para uma estrutura deste porte com $3 \mathrm{~m}$ de pé direito e com a montagem a cargo do cliente foi de $\mathrm{R} \$ 16.385,43$. Foi realizado o detalhamento de todos os materiais necessários à implantação estrutural do projeto com seus respectivos custos (Tabela 1).

Dentro da estufa, projetou-se a construção de duas bancadas de berçário de $0,70 \mathrm{~m} \times 8 \mathrm{~m}$ com 9 linhas de 8 $\mathrm{m}$ e 79 furos por linha, totalizando 711 furos por bancada. Para a fase de crescimento final, o projeto prevê seis bancadas de $1,4 \mathrm{~m}$ x $8 \mathrm{~m}$ com 7 linhas de perfil em cada bancada e 31 furos por linha totalizando 1.302 plantas. (Figura 1). 


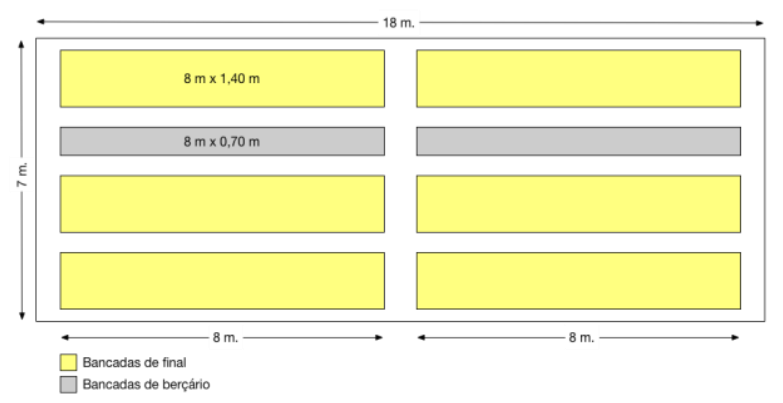

Figura 1: "Layout" simplificado sem escala das bancadas dentro da estufa

Tabela 1. Investimento para construção de estufa de $126 \mathrm{~m}^{2}$ e pé direito de $3 \mathrm{~m}$ para o projeto de hidroponia na cidade de São Paulo, SP

\begin{tabular}{|c|c|c|c|}
\hline \multirow{2}{*}{$\begin{array}{l}\text { Materiais para a estufa } \\
\text { (pé direito de } 3 \mathrm{~m} \text { ) }\end{array}$} & \multirow{2}{*}{ Quantidade } & \multicolumn{2}{|c|}{ Valor } \\
\hline & & unitário & total \\
\hline & & \multicolumn{2}{|c|}{---------R\$ --------- } \\
\hline $\begin{array}{l}\text { Parte aérea de } 7 \mathrm{~m} \text { x } 18 \\
\mathrm{~m} \text { com sistema de } \\
\text { molas incluso }\end{array}$ & 1 & $5.146,20$ & $5.146,20$ \\
\hline $\begin{array}{l}\text { Pés metálicos centrais } \\
\text { de } 5,75 \mathrm{~m}\end{array}$ & 2 & 200,00 & 400,00 \\
\hline $\begin{array}{l}\text { Pés metálicos laterais } \\
\text { de } 3,80 \mathrm{~m}\end{array}$ & 14 & 92,00 & $1.288,00$ \\
\hline $\begin{array}{l}\text { Cabeamento completo } \\
\text { para reforço da estufa }\end{array}$ & 1 & 448,75 & 448,75 \\
\hline $\begin{array}{l}\text { Tela anti-insetos de } 4 \mathrm{x} \\
100 \mathrm{~m}\end{array}$ & 1 & $2.956,00$ & $2.956,00$ \\
\hline $\begin{array}{l}\text { Tela antivírus } 50 \text { mesh } \\
\text { de } 4 \times 100 \mathrm{~m}\end{array}$ & 1 & $2.788,00$ & $2.788,00$ \\
\hline $\begin{array}{l}\text { Ráfia para cobertura de } \\
\text { solo de } 3,4 \times 50 \mathrm{~m}\end{array}$ & 1 & 642,60 & 642,60 \\
\hline $\begin{array}{l}\text { Porta de correr } \\
\text { metálica, vedada com } \\
\text { tela, de } 1,10 \times 2,20 \mathrm{~m} \\
\text { (pé direito de } 3 \mathrm{~m} \text { ) }\end{array}$ & 1 & 440,00 & 440,00 \\
\hline $\begin{array}{l}\text { Conector } 8 \text { fechado } \\
\text { (valor por unidade) }\end{array}$ & 1 & 0,68 & 0,68 \\
\hline Custo Total da Estufa & & & $16.385,43$ \\
\hline
\end{tabular}

O ciclo de produção da alface hidropônica é de 21 dias, ou seja, até 1.302 pés, totalizando uma produção de 1.860 pés de alface por mês. $O$ investimento nas bancadas da estufa foi orçado em $\mathrm{R} \$ 4.440,67$. Foram detalhados, neste valor, todos os materiais necessários à montagem destas (Tabela 2).

$\mathrm{O}$ investimento inicial envolveu, ainda, a aquisição dos equipamentos elétricos e materiais adicionais necessários para a operacionalização da horta. O investimento em equipamentos elétricos constando o detalhamento de todos os componentes necessários ao funcionamento do projeto foi orçado em $\mathrm{R} \$ 2.345,00$ (Tabela 3).
Tabela 2. Investimento das bancadas para o projeto hidropônico em São Paulo sem considerar o custo de montagem, SP

\begin{tabular}{|c|c|c|c|}
\hline \multirow{2}{*}{$\begin{array}{c}\text { Materiais para as } \\
\text { bancadas }\end{array}$} & \multirow{2}{*}{ Quantidade } & \multicolumn{2}{|c|}{ Valor } \\
\hline & & unitário & total \\
\hline & & \multicolumn{2}{|c|}{------ R\$ ------- } \\
\hline $\begin{array}{l}\text { Perfis TP58 } 4 \mathrm{~m} \text { com } \\
\text { furo } 10 \mathrm{~cm}\end{array}$ & 36 & 13,32 & 479,52 \\
\hline $\begin{array}{l}\text { Perfis R } 804 \mathrm{~m} \text { com } \\
\text { furo } 25 \mathrm{~cm}\end{array}$ & 84 & 22,80 & $1.915,20$ \\
\hline $\begin{array}{l}\text { Tampões de entrada } \\
\text { para perfil TP58 }\end{array}$ & 23 & 0,81 & 18,63 \\
\hline $\begin{array}{l}\text { Perfil de recolhimento } \\
\text { de } 0,75 \mathrm{~m} \times 9 \text { encaixes } \\
\text { TP58 }\end{array}$ & 2 & 13,35 & 26,70 \\
\hline Suportes para TP58 & 95 & 0,64 & 60,80 \\
\hline Tampões para R80 & 47 & 1,38 & 64,86 \\
\hline $\begin{array}{l}\text { Perfil de recolhimento } \\
\text { de } 1,45 \mathrm{~m} \text { x } 7 \text { encaixes } \\
\text { R80 }\end{array}$ & 6 & 25,81 & 154,86 \\
\hline Suportes para R80 & 131 & 0,78 & 102,18 \\
\hline $\begin{array}{l}\text { Sistema injetor de } \\
\text { solução completo }\end{array}$ & 65 & 2,20 & 143,00 \\
\hline $\begin{array}{l}\text { Canos em PP especial } \\
50 \mathrm{~mm} \times 6 \mathrm{~m}\end{array}$ & 4 & 26,27 & 105,08 \\
\hline $\begin{array}{l}\text { Canos em PP especial } \\
25 \mathrm{~mm} \times 6 \mathrm{~m}\end{array}$ & 4 & 15,56 & 62,24 \\
\hline $\begin{array}{l}\text { Perfil de bancada } \\
\text { barras de } 0,70 \mathrm{~m} \\
\text { (Travessa de cavalete) }\end{array}$ & 18 & 4,20 & 75,60 \\
\hline $\begin{array}{l}\text { Perfil de bancada } \\
\text { barras de } 1,40 \mathrm{~m} \\
\text { (Travessa de cavalete) }\end{array}$ & 42 & 8,40 & 352,80 \\
\hline $\begin{array}{l}\text { Pés de bancada de 1,20 } \\
\text { m (Pés de cavalete) }\end{array}$ & 120 & 7,20 & 864,00 \\
\hline Sela calha acrílica & 1 & 15,20 & 15,20 \\
\hline Custo total das bancada & hidroponia & & $4.440,67$ \\
\hline
\end{tabular}

Tabela 3. Investimentos em equipamentos elétricos para o projeto hidropônico em São Paulo, SP

\begin{tabular}{|c|c|c|}
\hline Equipamentos elétricos & Quantidade & Valor \\
\hline & & $--\mathrm{R} \$--$ \\
\hline Equipamento para emendas de perfis & 1 & 610,00 \\
\hline $\begin{array}{l}\text { Painel elétrico c/ relê, timer, liga- } \\
\text { desliga } 220 \mathrm{~V}\end{array}$ & 1 & 635,00 \\
\hline $\begin{array}{l}\text { Bomba centrifuga } 1 / 2 \mathrm{HP} \text { monofásica } \\
220 \mathrm{~V}\end{array}$ & 1 & 419,00 \\
\hline $\begin{array}{l}\text { Sucção: } 3 / 4 \text { " / Recalque: } 3 / 4 \text { " / Vazão } \\
\text { Máxima: } 8,6 \mathrm{~m}^{3} / \mathrm{h}\end{array}$ & & \\
\hline Peagâmetro digital & 1 & 200,00 \\
\hline Condutivíme & 1 & 265,00 \\
\hline $\begin{array}{l}\text { Kit de soluções de calibração para pH } \\
4, \mathrm{pH} 7 \text { e condutividade }(500 \mathrm{~mL})\end{array}$ & 1 & 216,00 \\
\hline Custo total & & $2.345,00$ \\
\hline
\end{tabular}

Os demais itens necessários para a horta encontram-se detalhados na tabela 4. Seus custos foram levantados em sítios eletrônicos especializados de acordo com a sua aplicação. Foi incluído nesta lista a aquisição de um veículo usado (ano 2014) para transporte de mercadorias. Todos os orçamentos foram 
agregados totalizando como investimento inicial o valor de $\mathrm{R} \$$ 60.665,90 (Tabela 5).

Tabela 4. Investimento para demais itens necessários para o projeto hidropônico em São Paulo, SP

\begin{tabular}{lccc}
\hline \multicolumn{1}{c}{ Itens } & \multirow{2}{*}{ Quantidade } & \multicolumn{2}{c}{ Valor } \\
& & unitário & total \\
\hline $\begin{array}{l}\text { Reservatório 1.500 L } \\
\text { para alface }\end{array}$ & 1 & 579,90 & 579,90 \\
$\begin{array}{l}\text { Registro de esfera (25 } \\
\text { mm) para bancadas }\end{array}$ & 8 & 12,99 & 103,90 \\
$\begin{array}{l}\text { Semeadora para } \\
\text { sementes peletizadas }\end{array}$ & 1 & 476,00 & 476,00 \\
$\begin{array}{l}\text { Kit de limpeza interna } \\
\text { de perfis (conexão }\end{array}$ & 2 & & \\
$\begin{array}{l}1 / 4 \text { " ou 5/16”) } \\
\text { Mesa de germinação } \\
\text { para 10 placas, de 1,15 }\end{array}$ & 1 & & \\
x 1,80 m & & & \\
$\begin{array}{l}\text { Torre de resfriamento } \\
\text { Trifásica - capacidade } \\
\text { até 5 mil litros }\end{array}$ & 1 & $5.400,00$ & $5.400,00$ \\
$\begin{array}{l}\text { Veículo para } \\
\text { transporte de } \\
\text { mercadorias (2014) }\end{array}$ & & & \\
\hline Custo total & 1 & $30.000,00$ & $30.000,00$ \\
\hline
\end{tabular}

Tabela 5. Estimativa do investimento total inicial do projeto hidropônico em São Paulo, SP

\begin{tabular}{lc}
\hline \multicolumn{1}{c}{ Orçamento } & Valor \\
\hline & $-------10.385,43$ \\
Estufa & $16 .-140,67$ \\
Bancadas & $2.345,00$ \\
Equipamentos elétricos & $37.494,80$ \\
Demais itens & $60.665,90$ \\
\hline Total
\end{tabular}

\section{Custos Fixos}

Agrupam os dispêndios relativos ao aluguel do terreno, mão de obra, taxas e despesas administrativas. O levantamento dos valores foi realizado via pesquisa de preço junto a empresas especializadas nestes ramos (Tabela 6).

Tabela 6. Custos fixos para o projeto hidropônico em São Paulo, SP

\begin{tabular}{lr}
\hline \multicolumn{1}{c}{ Item } & Valor anualizado \\
\hline & ------ R\$ ------ \\
Aluguel do terreno & $12.000,00$ \\
Mão de obra e encargos (1 funcionário) & $19.639,44$ \\
Taxas de funcionamento (alvará da & \\
prefeitura, fiscalização da vigilância & 600,00 \\
sanitária e bombeiros) & \\
Telefone & 298,80 \\
Produtos de limpeza & 50,00 \\
Assessoria contábil & $2.160,00$ \\
\hline Total dos custos fixos & $34.748,24$ \\
\hline
\end{tabular}

\section{Custos Variáveis}

Os custos dos insumos foram definidos com base em pesquisa de preços em sites especializados em produtos de hidroponia. Considerou-se que o controle fitossanitário será realizado inicialmente de forma preventiva com a adoção de boas práticas no manejo da horta. Dessa forma, não foi considerada a compra de defensivos na elaboração dos custos do projeto. Os demais custos de água e luz foram estimados a partir da estrutura montada para a horta hidropônica (Tabela 7).

Tabela 7. Custos variáveis para o projeto hidropônico em São Paulo, SP

\begin{tabular}{|c|c|c|c|}
\hline Item & $\begin{array}{l}\text { Valor } \\
\text { unitário }\end{array}$ & Quantidade & $\begin{array}{c}\text { Valor } \\
\text { anualizado }\end{array}$ \\
\hline & -- R\$ -- & & --- R\$ --- \\
\hline $\begin{array}{l}\text { Solução nutritiva - } \\
\text { saco de } 25 \mathrm{~kg}\end{array}$ & 142,00 & 3 & 426,00 \\
\hline $\begin{array}{l}\text { Nitrato de Cálcio saco } \\
\text { de } 25 \mathrm{~kg}\end{array}$ & 57,00 & 3 & 171,00 \\
\hline $\begin{array}{l}\text { Ferro EDDHA 6\% } \\
\text { saco } 1 \mathrm{~kg}\end{array}$ & 55,00 & 3 & 165,00 \\
\hline $\begin{array}{l}\text { Espuma fenólica (caixa } \\
\text { com } 10.350 \text { células) }\end{array}$ & 106,00 & 3 & 318,00 \\
\hline $\begin{array}{l}\text { Bandeja para espuma } \\
\text { fenólica }\end{array}$ & 22,40 & 5 & 112,00 \\
\hline $\begin{array}{l}\text { Semente de alface } \\
\text { Crocante "Brunela" } \\
\text { (segmento gourmet - } \\
\text { mini-alface frizeé) - } 5 \\
\text { mil }\end{array}$ & 168,00 & 5 & 840,00 \\
\hline $\begin{array}{l}\text { Embalagem (caixa com } \\
4.000 \text { unidades) }\end{array}$ & 338,00 & 6 & $2.028,00$ \\
\hline Água (até 10 m³/mês) & 45,00 & 12 & 540,00 \\
\hline $\begin{array}{l}\text { Energia Elétrica } \\
(\mathrm{KWh})\end{array}$ & 0,238 & 9.000 & $2.142,00$ \\
\hline Total dos custos variávei & & & $6.742,00$ \\
\hline
\end{tabular}

\section{Depreciação}

O cálculo da depreciação foi realizado de forma linear de acordo com a tabela de depreciação da Secretaria da Receita Federal (2016) (Tabela 8).

Tabela 8. Cálculo da depreciação anual dos bens do projeto de hidroponia tradicional

\begin{tabular}{lrrrr}
\hline \multicolumn{1}{c}{ Bens } & Valor do bem & & Depreciação & Vida útil \\
\hline $\begin{array}{l}\text { Estufa } \\
\begin{array}{l}\text { Veículo para } \\
\text { transporte de }\end{array}\end{array}$ & $16.385,43$ & 4 & 655,42 & 25 \\
$\begin{array}{l}\text { mercadorias } \\
\text { Bancadas }\end{array}$ & $40.000,00$ & 20 & $6.000,00$ & 4 \\
$\begin{array}{l}\text { Equipamentos } \\
\text { elétricos }\end{array}$ & $2.345,00,67$ & 10 & 444,07 & 10 \\
$\begin{array}{l}\text { Demais itens } \\
\text { de instalação }\end{array}$ & $7.494,80$ & 10 & 234,50 & 10 \\
\hline
\end{tabular}


No caso do veículo, por se tratar de um modelo usado, o veículo já possuía um ano de depreciação. Com isso, foram depreciados apenas quatro anos, seguindo a legislação vigente.

\section{Receita}

Para a definição do preço de venda da alface hidropônica, foi considerada a média dos valores pagos ao atacadista na cidade de São Paulo nos últimos 12 meses de acordo com levantamento feito por HF Brasil (2016) (Figura 2).

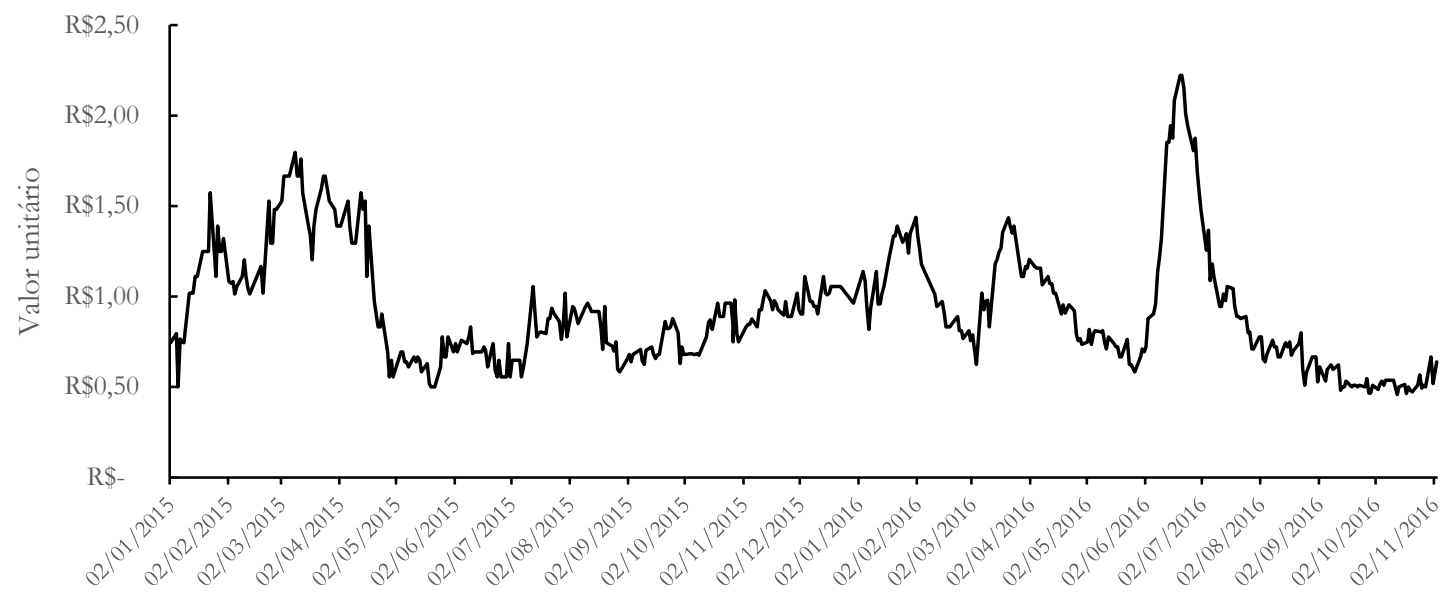

Figura 2. Variação do preço da alface pago aos atacadistas da cidade de São Paulo, SP

Fonte: adaptado de HF Brasil (2016)

A partir da base histórica de preço, foi definido valor de $\mathrm{R} \$ 0,93$ como o preço unitário do pé de alface. Considerando estimativa de produção de 1.860 pés de alface por mês, ou seja, 22.320 pés por ano, espera-se atingir no projeto de hidroponia tradicional receita anual de $\mathrm{R} \$ 20.757,60$.

\section{Projeto de Hidroponia Vertical}

O projeto vertical previu a construção das bancadas para o suporte da alface dentro de um galpão, excluindo a necessidade de construção de uma estufa. O tamanho do galpão considerado foi o mesmo do terreno, ou seja, $10 \mathrm{~m}$ x $20 \mathrm{~m}$ (Tabela 9).

Esta estrutura de bancadas foi projetada com iluminação artificial de LED, com vida útil de 13 anos, possibilitando a otimização do uso do espaço, pois neste tipo de sistema de produção, dada a flexibilidade na disponibilidade e posicionamento da luz, é possível a valer-se de vários andares de horta.

Kozai et al. (2014) relatou que o formato mais comum deste tipo de empreendimento se utiliza de 4 a 16 andares (ou camadas) de horta. Utilizando a mesma arquitetura definida na Figura 1, definiu-se a utilização de quatro andares de bancadas de horta hidropônica. A produção estimada por ciclo de produção (21 dias) é de 5.208 pés de alface ou 7.740 alfaces por mês $(89.280$ alfaces por ano) totalizando uma receita anual de $\mathrm{R} \$$ $83.030,40$.
Tabela 9. Investimento para construção das bancadas para o projeto de hidroponia vertical em ambiente fechado na cidade São Paulo, SP

\begin{tabular}{|c|c|c|c|}
\hline \multirow{2}{*}{ Materiais para as bancadas } & \multirow{2}{*}{ Quantidade } & \multicolumn{2}{|c|}{ Valor } \\
\hline & & unitário & total \\
\hline & & \multicolumn{2}{|c|}{----- R\$ ------ } \\
\hline $\begin{array}{l}\text { Perfis TP58 } 4 \mathrm{~m} \text { com furo } \\
10 \mathrm{~cm}\end{array}$ & 144 & 13,32 & $1.918,08$ \\
\hline $\begin{array}{l}\text { Perfis R80 } 4 \mathrm{~m} \text { com furo } 25 \\
\mathrm{~cm}\end{array}$ & 336 & 22,80 & $7.660,80$ \\
\hline $\begin{array}{l}\text { Tampões de entrada para } \\
\text { perfil TP58 }\end{array}$ & 92 & 0,81 & 74,52 \\
\hline $\begin{array}{l}\text { Perfil de recolhimento de } \\
0,75 \mathrm{~m} \times 9 \mathrm{~m} \text { encaixes TP58 }\end{array}$ & 8 & 13,35 & 106,80 \\
\hline Suportes para TP58 & 380 & 0,64 & 243,20 \\
\hline Tamp & 188 & 1,38 & 259,44 \\
\hline $\begin{array}{l}\text { Perfil de recolhimento de } \\
1,45 \mathrm{~m} \times 7 \mathrm{~m} \text { encaixes } \mathrm{R} 80\end{array}$ & 24 & 25,81 & 619,44 \\
\hline Suportes para R80 & 524 & 0,78 & 408,72 \\
\hline $\begin{array}{l}\text { Sistema injetor de solução } \\
\text { completo }\end{array}$ & 260 & 2,20 & 572,00 \\
\hline $\begin{array}{l}\text { Canos em PP especial } 50 \\
\mathrm{~mm} \times 6 \mathrm{~m}\end{array}$ & 16 & 26,27 & 420,32 \\
\hline $\begin{array}{l}\text { Canos em PP especial } 25 \\
\mathrm{~mm} \times 6 \mathrm{~m}\end{array}$ & 16 & 15,56 & 248,96 \\
\hline $\begin{array}{l}\text { Perfil de bancada barras de } \\
0,70 \mathrm{~m}\end{array}$ & 72 & 4,20 & 302,40 \\
\hline $\begin{array}{l}\text { Perfil de bancada barras de } \\
1,40 \mathrm{~m}\end{array}$ & 168 & 8,40 & $1.411,20$ \\
\hline Pés de bancada de 1,20 m & 480 & 7,20 & $3.456,00$ \\
\hline Selacalha acrílica & 4 & 15,20 & 60,80 \\
\hline Custo total das bancadas d & & & 762,68 \\
\hline
\end{tabular}


O investimento na parte elétrica possui similaridade com o que foi detalhado no sistema anterior (hidroponia tradicional) (Tabela 3). Dado que o sistema a ser desenvolvido será em local fechado utilizando iluminação artificial, foram considerados adicionalmente a iluminação de LED e a instalação de exaustores para eliminação do calor gerado pelos equipamentos elétricos. Os valores foram levantados através de pesquisa de preços em sítios eletrônicos especializados na venda de materiais para hidroponia e, somados, totalizam valor de $\mathrm{R} \$ 20.495,48$ (Tabela 10).

Tabela 10. Investimento da parte elétrica para demais itens necessários para o projeto de hidroponia vertical na cidade de São Paulo, SP

\begin{tabular}{|c|c|c|c|}
\hline \multirow{2}{*}{ Equipamentos elétricos } & \multirow{2}{*}{ Quantidade } & \multicolumn{2}{|c|}{ Valor } \\
\hline & & unitário & total \\
\hline & & \multicolumn{2}{|c|}{------ R\$ -------- } \\
\hline $\begin{array}{l}\text { Equipamento para } \\
\text { emendas de perfis }\end{array}$ & 1 & 610,00 & 610,00 \\
\hline $\begin{array}{l}\text { Painel elétrico com relê, } \\
\text { timer, liga-desliga } 220 \mathrm{~V}\end{array}$ & 1 & 635,00 & 635,00 \\
\hline $\begin{array}{l}\text { Bomba centrifuga } 1 / 2 \\
\text { H.P monofásica } 220 \mathrm{~V}\end{array}$ & & & \\
\hline $\begin{array}{l}\text { Sucção: 3/4" / Recalque: } \\
\text { 3/4" / Vazão Máxima: } \\
8,6 \mathrm{~m}^{3} / \mathrm{h}\end{array}$ & 1 & 419,00 & 419,00 \\
\hline Peagâmetro digital & 1 & 200,00 & 200,00 \\
\hline Condutivímetro digital & 1 & 265,00 & 265,00 \\
\hline $\begin{array}{l}\text { Kit de soluções de } \\
\text { calibração para } \mathrm{pH} 4, \mathrm{pH} \\
7 \text { e condutividade }(500 \\
\mathrm{mL})\end{array}$ & 1 & 216,00 & 216,00 \\
\hline $\begin{array}{l}\text { Grow Led Hidroponia } \\
20 \mathrm{~W} \text { (durabilidade de } \\
50.000 \text { horas) }\end{array}$ & 92 & 89,99 & $17.278,08$ \\
\hline Exaustor $(200 \mathrm{~W})$ & 6 & 145,40 & 872,40 \\
\hline Custo Total dos equipar & elétricos & & $20.495,48$ \\
\hline
\end{tabular}

Os demais itens necessários para a horta encontram-se detalhados na Tabela 4 e são os mesmos do projeto anterior. Embora a produção do projeto de hidroponia vertical seja maior, a quantidade desses itens continua adequada. A somatória dos orçamentos totalizou um investimento inicial no valor de $\mathrm{R} \$$ 75.752,96 (Tabela 11).

Tabela 11. Investimento inicial para o projeto de horta hidropônica vertical em São Paulo, SP

\begin{tabular}{lr}
\hline \multicolumn{1}{c}{ Orçamento } & Valor \\
\hline & --- \\
Bancadas & $17.762,68$ \\
Equipamentos elétricos & $20.495,48$ \\
Demais itens & $37.494,80$ \\
\hline Total & $75.752,96$ \\
\hline
\end{tabular}

\section{Custos Fixos}

Os custos fixos foram semelhantes ao projeto de hidroponia tradicional diferenciando no tipo do imóvel a ser locado. Em virtude de se tratar de uma edificação, os custos para este projeto foram superiores ao anterior, totalizando valor de $\mathrm{R} \$ 42.068,24$ ao ano (Tabela 12 ).

Tabela 12. Custos fixos para o projeto vertical em São Paulo, SP

\begin{tabular}{lr}
\hline \multicolumn{1}{c}{ Item } & \multicolumn{1}{c}{ Valor anualizado } \\
\hline & \multicolumn{1}{c}{------ R $\$$----- } \\
Aluguel do galpão & $19.200,00$ \\
Mão de obra e encargos (1 funcionário) & $19.639,44$ \\
Taxas de funcionamento (alvará da & \\
prefeitura, fiscalização da vigilância & 600,00 \\
sanitária e bombeiros) & \\
Telefone & 298,80 \\
Produtos de limpeza & 170,00 \\
Assessoria contábil & $2.160,00$ \\
\hline Total dos custos fixos & $42.068,24$ \\
\hline
\end{tabular}

Apesar do maior número de plantas nesse projeto, o número de funcionários não aumentou pois, conforme (SEBRAE, 2016), um único funcionário consegue cuidar de aproximadamente 10.000 plantas.

\section{Custos Variáveis}

Em virtude da maior produção de alface e da iluminação de LED, os custos variáveis deste projeto são maiores totalizando o valor anual $\mathrm{R} \$ 23.178,27$ (Tabela 13).

Tabela 13. Custos variáveis para o projeto vertical em São Paulo, SP

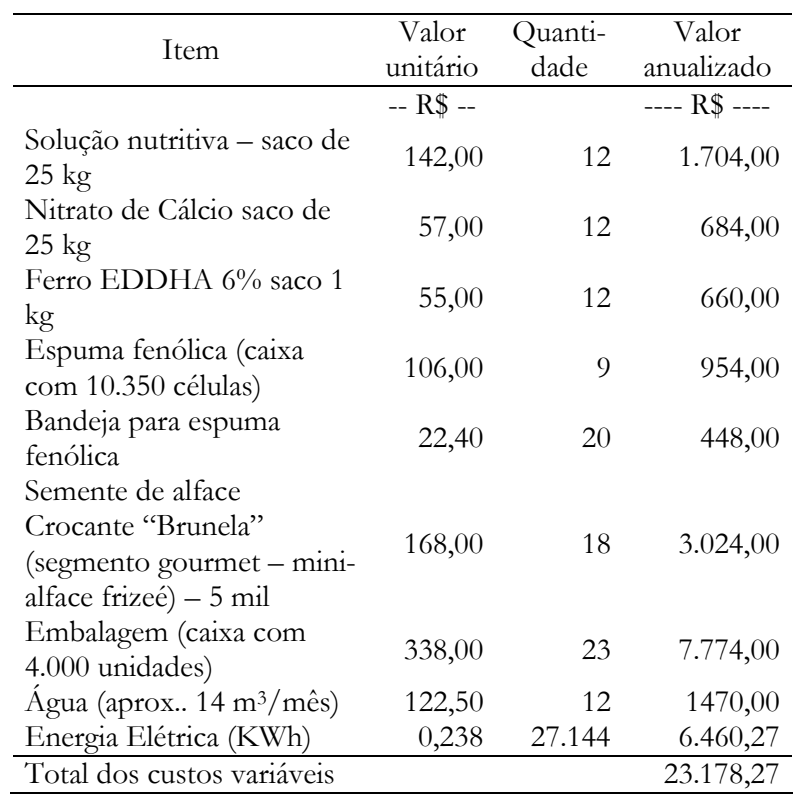

\section{Depreciação}

O cálculo da depreciação foi realizado de forma análoga ao projeto de hidroponia tradicional. Como o imóvel é alugado, o mesmo não foi considerado na depreciação (Tabela 14). 
Tabela 14. Cálculo da depreciação anual dos bens do projeto de hidroponia vertical

\begin{tabular}{lrrrr}
\hline \multicolumn{1}{c}{ Bens } & Valor do bem & & Depreciação & $\begin{array}{r}\text { Vida } \\
\text { útil }\end{array}$ \\
\hline $\begin{array}{l}\text { Veículo para } \\
\text { transporte de } \\
\text { mercadorias }\end{array}$ & ----- R\$----- & $-\%$ - & ---- R\$ ----- & anos \\
$\begin{array}{l}\text { Bancadas } \\
\begin{array}{l}\text { Equipamentos } \\
\text { elétricos }\end{array}\end{array}$ & $17.762,68$ & 10 & $1.776,27$ & 10 \\
$\begin{array}{l}\text { Demais itens de } \\
\text { instalação }\end{array}$ & $20.495,48$ & 10 & $2.049,55$ & 10 \\
& $7.494,80$ & 10 & 749,48 & 10 \\
\hline
\end{tabular}

Impostos que incidem sobre ambas categoria

A partir do faturamento esperado para os dois projetos foi considerada a opção pelo Simples Nacional. A alíquota aplicada foi de $4 \%$ sobre a receita bruta acumulada no ano.

\section{Taxa Mínima de Atratividade [TMA]}

Para o cálculo da TMA, considerou-se meta de $14 \%$, referente a taxa referencial do Sistema Especial de Liquidação e Custódia [SELIC] de novembro de 2016, descontada da projeção do índice de inflação para 2016 [IPCA], projetado em 6,88\% (BCB, 2016). Desta forma, a taxa utilizada foi de $6,66 \%$ a.a.

\section{Indicadores de Rentabilidade}

Para a análise de viabilidade financeira foram utilizados os indicadores Valor Presente Líquido [VPL], Taxa Interna de Retorno [TIR] e "Payback" Descontado, descritos em Souza et al. (2008).

\section{Resultados e Discussão}

A partir dos dados apresentados, foi elaborado fluxo de caixa para período de 13 anos, que corresponde ao período de vida útil das lâmpadas de LED. Em ambos os projetos foi considerada uma produção constante de alface durante o período analisado. A receita bruta e os custos foram atualizados anualmente pela projeção do IPCA para o ano de 2016. A título de exemplo, a receita bruta estimada e o imposto devido no primeiro ano estão descritos na Tabela 15.

Tabela 15. Valor anual do imposto a ser pago no primeiro ano de funcionamento para cada um dos projetos

\begin{tabular}{lcr}
\hline \multicolumn{1}{c}{ Projeto } & Receita bruta & $\begin{array}{c}\text { Imposto devido } \\
\text { no ano }\end{array}$ \\
\hline & ------------ $\mathrm{R} \$$ & ------------ \\
\hline Hidroponia tradicional & $20.757,60$ & 830,30 \\
Hidroponia vertical & $88.742,89$ & $3.549,72$ \\
\hline
\end{tabular}

O projeto de hidroponia tradicional apresentou prejuízo acumulado de $-\mathrm{R} \$ 538.834,52$ ao final do $13^{\circ}$ ano do projeto, sendo considerado inviável (Figura 3).

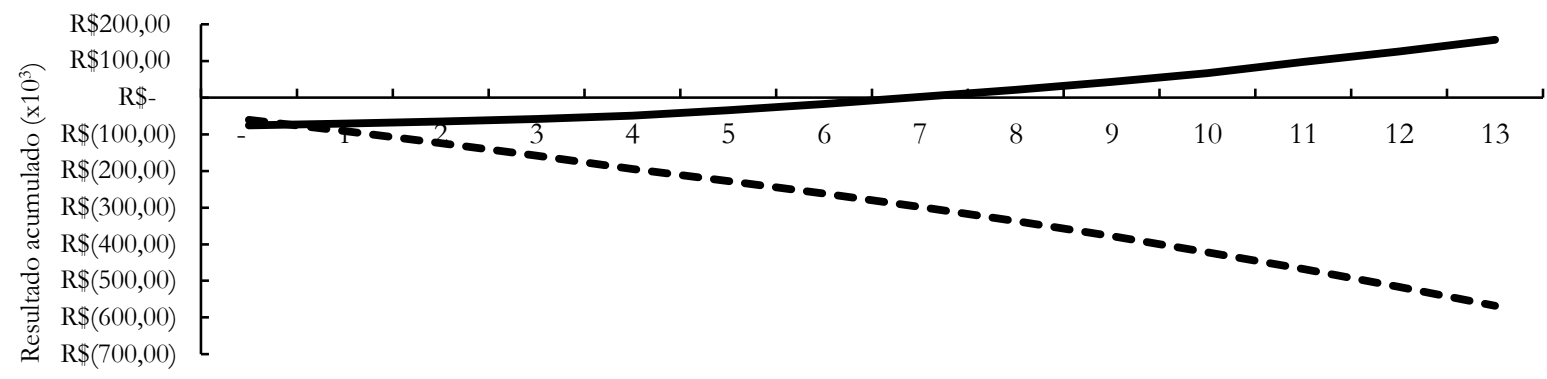

- Hidroponia tradicional Hidroponia vertical

Figura 3. Resultado acumulado dos projetos no período de 13 anos

No caso do projeto de hidroponia vertical, o investimento inicial foi maior ( $\mathrm{R} \$ 75.752,96)$, em virtude dos andares adicionais de bancadas e da iluminação de LED (Tabela 10). Apesar disto, o projeto obteve ganho de escala, com menor custo por hortaliça produzida, atingindo o retorno do capital investido em aproximadamente 6 anos e 11 meses (Figura 3). Utilizando TMA de 6,66\% ao ano, obteve-se VPL igual a R\$ 59.350,50 e uma TIR de 15,01\% (Tabela 16). Os equipamentos adicionais do projeto vertical causaram um aumento $244 \%$ nos custos variáveis e $21 \%$ nos custos fixos do projeto (Figura 4A).
Tabela 16. Indicadores econômicos obtidos para os projetos de hidroponia

\begin{tabular}{|c|c|c|c|}
\hline Projeto & $\begin{array}{l}\text { Valor } \\
\text { Presente } \\
\text { Líquido }\end{array}$ & $\begin{array}{c}\text { Taxa } \\
\text { Interna de } \\
\text { Retorno }\end{array}$ & $\begin{array}{l}\text { "Payback" } \\
\text { descontado }\end{array}$ \\
\hline & ----- R\$ ----- & $--\%$ & \\
\hline $\begin{array}{l}\text { Hidroponia } \\
\text { tradicional }\end{array}$ & $(381.286,26)$ & - & - \\
\hline $\begin{array}{l}\text { Hidroponia } \\
\text { vertical }\end{array}$ & $59.350,50$ & 15,01 & $\begin{array}{r}6 \text { anos e } 11 \\
\text { meses }\end{array}$ \\
\hline
\end{tabular}


(A)

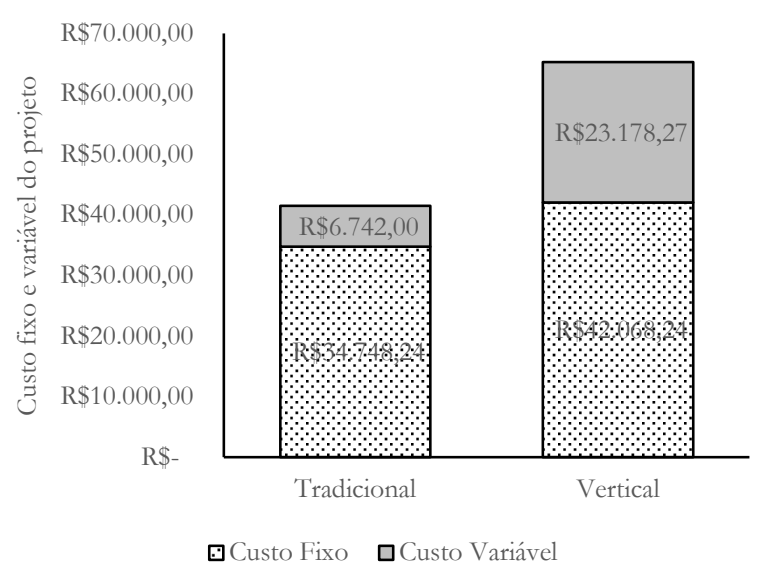

(B)

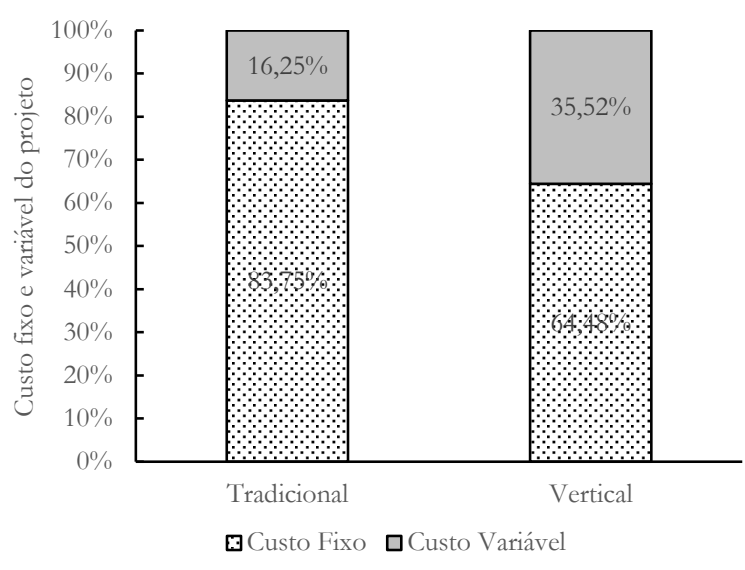

Figura 4. Custos dos projetos em São Paulo, SP; (A) em reais e (B) em porcentagem

Analisando a relação dos custos entre os projetos, verifica-se que no projeto vertical houve uma redução no impacto do custo fixo de $83,75 \%$ (projeto tradicional) para $64,48 \%$ (Figura $4 \mathrm{~B}$ ).

Em comparação com o projeto de hidroponia tradicional, o ganho de escala obtido no projeto vertical através do "empilhamento" de vários andares de bancadas de alface foi fundamental na viabilidade do projeto. Dessa forma, essa abordagem minimizou os impactos dos custos mais altos de implantação do projeto em ambiente urbano se comparados com um projeto tradicional em uma propriedade rural. Os indicadores calculados para o projeto de hidroponia vertical mostram que este projeto é viável.

\section{Análise de Sensibilidade}

A análise de sensibilidade considerou a sistemática do projeto vertical aplicado a hortas de 4 a 16 andares de cultivo de alface hidropônica. O investimento inicial e os custos variáveis foram atualizados na proporção em que os andares foram adicionados à análise, seguindo a mesma sistemática utilizada no projeto vertical original.

O cálculo dos custos fixos foi realizado considerando a métrica de que um funcionário é capaz de cuidar de 10.000 plantas mês (SEBRAE, 2016). Desta forma, foi considerado a inclusão de novos funcionários para atender a produção estimada em cada cenário.

A análise considerou, ainda, a mudança no valor da alíquota incidente para cálculo do imposto a pagar observando a estimativa de receita para cada ano (Brasil, 2006).

As quedas periódicas no valor da TIR (Figura 5) ocorreram principalmente pela mudança no valor da alíquota de imposto e no número de funcionários.

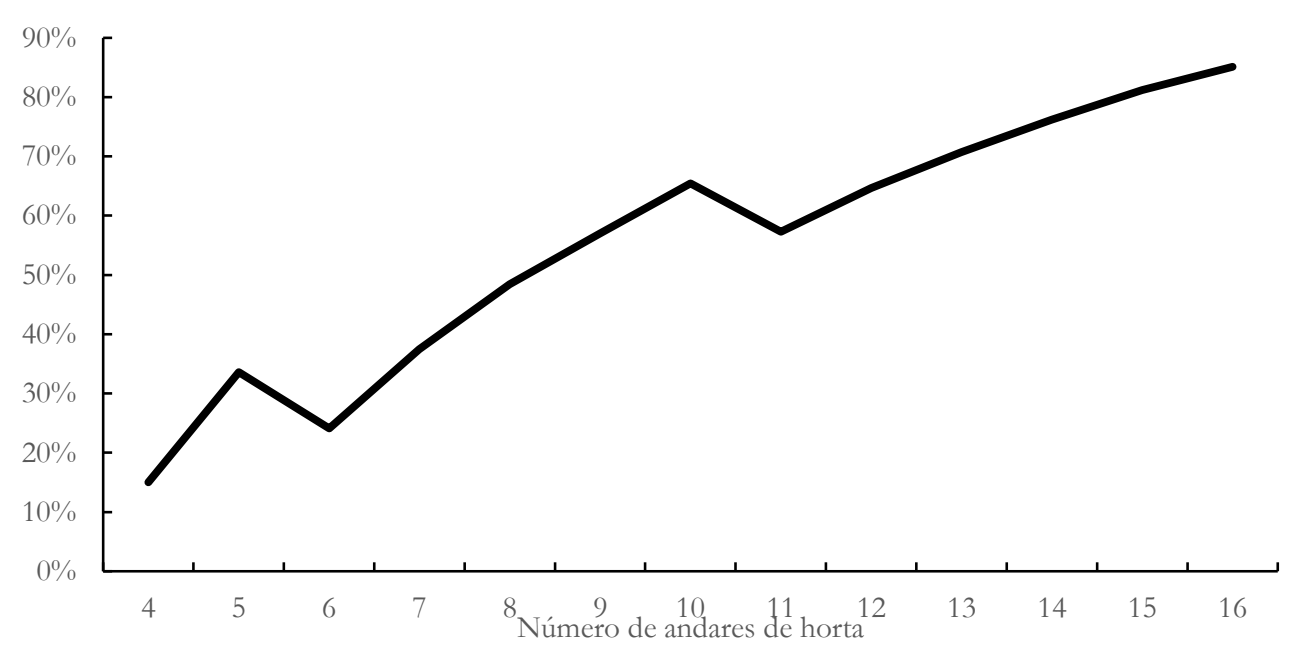

Figura 5. Variação da Taxa Interna de Retorno [TIR] de acordo com o número de andares utilizados para um projeto com iluminação artificial em São Paulo, SP 
Utilizando a análise para calcular o custo de produção por alface verifica-se que a inclusão de novos andares, via de regra, acaba reduzindo o custo de produção (Figura 6).
De forma análoga ao gráfico da variação da TIR (Figura 5), os incrementos no preço unitário da alface ocorreram nos andares em que houve mudança na alíquota de imposto e no número de funcionários.

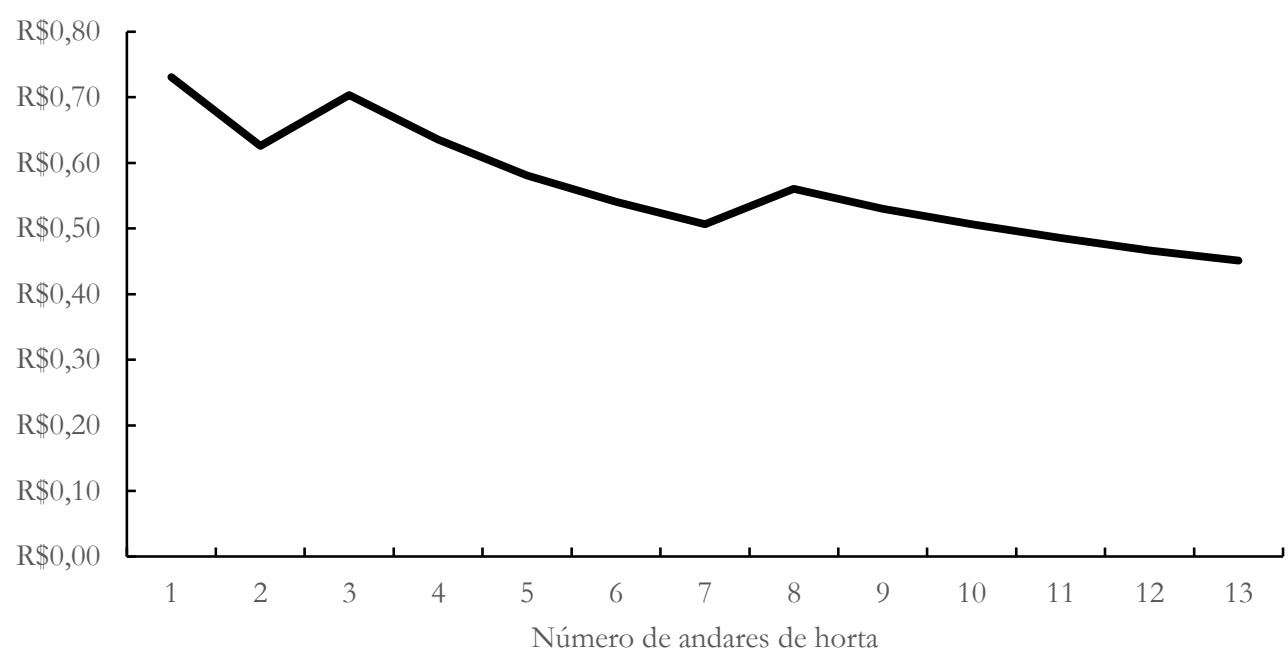

Figura 6. Variação do custo de produção de um pé de alface de acordo com o número de andares utilizados para um projeto com iluminação artificial em São Paulo, SP

A inclusão de equipamentos que permitam melhor controle de temperatura, humidade e $\mathrm{CO}_{2}$ aumentam consideravelmente a produtividade da horta (Kozai et al., 2014). A evolução do valor da TIR, mostrada na Figura 5, permite conjecturar que o investimento e os custos de inclusão destes equipamentos tecnológicos poderiam ser diluídos pelo aumento de andares no projeto.

\section{Conclusão}

O fluxo de caixa dos projetos, considerando um horizonte de 13 anos e receita definida pela média dos valores pagos ao atacadista na cidade de São Paulo nos últimos 12 meses, apresentou VPL negativo para o projeto de hidroponia tradicional e positivo para o projeto de hidroponia vertical. No segundo projeto, além de positivos, os valores encontrados nos indicadores foram atrativos considerando que 0 "payback" do projeto deverá ocorrer em 6 anos e 11 meses, um pouco depois da metade do período analisado, e a TIR, calculada em 15,01\%, deixa uma boa margem para oscilação na taxa real de juros.

Através da análise de sensibilidade verificou-se que a inclusão de novos andares no projeto de horta vertical melhora o desempenho da TIR e reduz o custo de produção por alface.

Em face dos resultados, a implantação de uma horta hidropônica no sistema vertical em um galpão localizado dentro da área urbana da cidade de São Paulo, é viável.

\section{Referências}

Banco Central do Brasil [BCB]. 2016. Fócus - Relatório de mercado. Disponível em:

<https://www.bcb.gov.br/pec/GCI/PORT/readout /R20161028.pdf>. Acesso em: 04 nov. 2016.

Brasil. 2006. Lei Complementar No 123 de 14 de dezembro de 2006. Disponível em:

$<$ http://www.planalto.gov.br/ccivil_03/leis/LCP/Lc p123.htm>. Acesso em: 05 nov. 2016.

Fundação Sistema Estadual de Análise de Dados [SEADE]. 2016. Projeções Populacionais. Disponível em:

$<$ http://produtos.seade.gov.br/produtos/projpop/in dex.php>. Acesso em: 05 nov. 2016.

Departamento Nacional de Trânsito [DENATRAN]. 2016. Frota de Veículos - 2016. Disponível em: <http://www.denatran.gov.br/images/Estatistica/R ENAVAM/2016/Dezembro/Frota_por_Municipio_ e_Tipo-DEZ_16.xlsx>. Acesso em: 16 jun. 2017.

HF Brasil. 2016. Preços Médios dos Hortifrutícolas. Disponível em:

<http://www.hfbrasil.org.br/br/banco-de-dadosprecos-medios-dos-hortifruticolas.aspx $>$. Acesso em: 04 nov. 2016.

Fonseca, J. W. F. 2012. Elaboração e análise de projetos: a viabilidade econômico-financeira. Editora Atlas, São Paulo, SP, Brasil.

Kozai, T.; Niu, G.; Takagaki, M. 2014. Plant factory: an indoor vertical farming system for eficient quality food production. Elsevier, London, UK. 
Organização das Nações Unidas [ONU]. 2017. World Population Prospects: The 2017 Revision. Disponível em: <https://esa.un.org/unpd/wpp/>. Acesso em: 04 nov. 2017.

Prefeitura de São Paulo. 2016. Dados demográficos dos distritos pertencentes às subprefeituras. Disponível em: <http://www.capital.sp.gov.br/portal/>. Acesso em: 05 nov. 2016.

Resh, H. M. 2013. Hidroponic food production. CRC Press, Boca Raton, FW, US.

Secretaria da Receita Federal do Brasil [SRFB]. 2016. Tabela de depreciação. Disponível em: $<$ http://idg.receita.fazenda.gov.br/interface/empresa >. Acessado em: 05 nov. 2016.

Secretaria da Receita Federal do Brasil [SRFB]. 2016. Tabela de depreciação. Disponível em: $<$ http://idg.receita.fazenda.gov.br/interface/empresa >. Acessado em: 05 nov. 2016.

Serviço Brasileiro de Apoio às Micro e Pequenas Empresas [SEBRAE]. 2016. Como montar uma hidroponia. Disponível em: <https://www.sebrae.com.br/sites/PortalSebrae/idei as/como-montar-uma-hidroponia>. Acesso em: 05 nov. 2016.

Souza, A.; Clemente, A. 2008. Decisões financeiras e análise de investimentos: fundamentos, técnicas e aplicações. Editora Atlas, São Paulo, SP, Brasil. 